\title{
LA MODA DEL "MONAGUILLISMO" EN LOS PINTORES ANDALUCES DE ENTRE SIGLOS
}

\author{
THE TREND OF “MONAGUILLISMO” IN THE \\ ANDALUSIAN PAINTERS AT THE TURN \\ OF THE CENTURY
}

\author{
Gerardo Pérez Calero \\ Universidad de Sevilla. España \\ gcalero@us.es
}

Este trabajo trata de una moda que apareció en la pintura española entre los siglos XIX y XX como consecuencia del preciosismo fortuniano y la pintura social.

Palabras clave: monaguillismo; pintura; España; Andalucía; entre siglos.

This paper deals with a trend that appeared in Spanish painting between the $19^{\text {th }}$ and $20^{\text {th }}$ centuries as a consequence of Fortuny's preciosity and the social painting.

Keywords: monaguillismo; painting; Spain; Andalusia; turn of the century.

\section{INTRODUCCIÓN}

Con el destronamiento de Isabel II en 1868 se produjo un profundo cambio político y social en la España decimonónica que afectaría también a la cultura y a las artes ${ }^{1}$. Como consecuencia, el costumbrismo que estuvo en vigor en la pintura durante la era romántica o isabelina deja paso a otros géneros de corte realista como el cuadro de historia y el paisaje.

${ }^{1}$ Sobre la incidencia de la Revolución de 1868 y las artes en España, véase HERNANDO CARRASCO, J.: Las Bellas Artes y la Revolución de 1868. Oviedo, 1987. 
Sin embargo, la irrupción del reusense Mariano Fortuny en la pintura española desde la sexta década y su poderoso arraigo en la siguiente renovará aquel romanticismo que parecía desaparecer en una suerte de neorromanticismo preciosista que apela a soslayar el dibujo en aras del empleo vigoroso del color.

Por otra parte, el realismo naturalista procedente de Francia desde los comedios de siglo afectaría más tarde también a la pintura española mediante la práctica de temas vulgares y cotidianos que llegaron a identificarse con la delicada cuestión social que se vivía en el país.

Una y otra estética pusieron en boga, tanto el cuadrito -tableautin- fortuniano caracterizado por su preciosismo miniaturista que recordaba la pintura francesa de estilo Luis XV, como el cuadro llamado de "tesis" de asuntos intrascendentes.

Una variante que se nutre de ambas formas de interpretar la pintura -el fortunismo y el cuadro de tesis- es la que ahora nos ocupa en este trabajo: el llamado "monaguillismo", término aparentemente convencional y cargado de prejuicios para una crítica que no supo o no quiso valorarlo en su justo término como ocurrió también con la pintura de historia ${ }^{2}$. Hoy debemos juzgar con otra perspectiva un género que para bien o para mal acaparó el interés de los artistas y por ende de la crítica en plena edad de plata de la cultura española, que hemos de ver y estudiar como uno más de los que tenían referencias sociales en la España del llamado "turno pacífico" (1881-1923) de Cánovas y Sagasta en tiempos de la Restauración borbónica (1875-1923).

Por entonces, era bien visto en el salón de cualquier casa burguesa que se preciase un cuadro de pared con un niño de sotanilla escarlata, alas almidonadas de la sobrepelliz angélica, el hisopo y el acetre en las manos, deambulando por el interior de la iglesia, capilla bautismal o coro haciendo alguna graciosa travesura.

Convencido, pues, de la necesidad de ayudar a difundir su conocimiento y estimular su estudio, ofrecemos esta síntesis como un acercamiento al estado actual de la cuestión.

En rigor, la presencia del acólito, monaguillo o servidor de altar en la pintura europea y española no es nueva pues se representó esporádicamente con anterioridad al marco cronológico antes señalado ${ }^{3}$. Desde el Romanticismo, esta figura infantil se asocia a los rituales eclesiásticos de manera pasiva sin protagonismo

${ }^{2}$ Gaya Nuño denostaba ambos temas, aludiendo a "anatomía de un error" respecto a la pintura de historia, y llamando "grave enfermedad", entre otras variantes temáticas, al "monaguillismo", al que calificó de "lamentable" e "imbécil género". GAYA NUÑO, Juan Antonio: Arte del siglo XIX. Madrid, 1966.

${ }^{3}$ En pleno Romanticismo el monago aparecía como figura más o menos "retórica" en cuadros costumbristas. Tal es el caso, a modo de ejemplos, de pintores como Francisco Cabral Bejarano (Interior de una iglesia durante una misa), Juan José de Urmeneta (Capuchinos en el coro), Joaquín Manuel Fernández Cruzado (Misa mayor), Manuel Rodríguez de 
aparente ${ }^{4}$. Más tarde, cambiará el papel jugado por el monago, que pasará a adquirir la mayor y a veces exclusiva atención del artista.

Los pintores andaluces pertenecientes a la generación realista de entre siglos se involucraron en un género, temática o variante pictórica como el que nos ocupa por diversos motivos que conviene señalar. El primero de todos es el arraigo de la tradición costumbrista de tradición murillesca que desde el siglo XVIII existía en la región; en segundo lugar, el afianzamiento del pintoresquismo desde los inicios de la siguiente centuria acrecentado por el posterior neorromanticismo de los andaluces de la llamada escuela de Roma; por fin, las circunstancias sociales que vivía Andalucía desde la Restauración alfonsina.

Vinculantes son en este panorama las consecuencias del éxito rotundo que tuvo Fortuny en París con su cuadro La vicaría, ya que fueron numerosos los pintores, muchos andaluces, que pusieron en el mercado internacional de arte tableautines a veces ejecutados en Roma, ciudad en la que muchos de ellos residían, que representaban circunstancias marginales del ritual que acompañaban algunos ceremoniales religiosos, como bodas, bautizos, comuniones o fallecimientos. Esos momentos tenían como ubicación la propia sacristía del templo donde se celebraron. Tal estancia se convertirá, pues, en un "espacio ambiguo, mitad sagrado mitad profano, que en sí mismo es, también, un preludio o un después intrascendente entre la solemnidad de la iglesia y la alegría de la calle"5.

Si las anteriormente mencionadas se consideran escenas de interior, hay otras en las que los mismos protagonistas -fieles, contrayentes, clérigos y monaguillosse sitúan al aire libre en procesiones que discurren con frecuencia por el casco histórico de ciudades monumentales andaluzas, preferentemente Sevilla, Córdoba y Granada, e italianas, sobre todo Roma y Venecia.

Este tipo de representación de carácter escenográfico está presente con más o menos fortuna en las escuelas artísticas de Sevilla, Cádiz, Jerez de la Frontera, Málaga y Granada.

Guzmán (Caballero ante un clérigo y un monaguillo) o José María Romero (Beatas y monaguillo en la sacristía).

${ }^{4}$ El término "monaguillo" procede de monjes pequeños. Se escoge la palabra acólito, reservando el vocablo "monaguillo" para los ministros extraordinarios o de hecho, o sea que no han sido nombrados solemnemente y no pertenecen a un "colegio" de acólitos o que ejercen tales funciones de forma esporádica. Los monaguillos son acólitos "de hecho", que, sin haber sido instituidos en el ministerio de acólitos, lo ejercen regularmente en las celebraciones litúrgicas con fieles. Sus cometidos son diversos, entre ellos: atender al servicio del altar, ayudar al obispo, al sacerdote y al diácono, prestar su servicio en las diversas procesiones, por ejemplo con la cruz, los cirios, el incienso o el misal, atender en el ofertorio a la recogida de los dones, etc.

${ }_{5}$ REYERO, Carlos: Ternura y melodrama. Pintura de escenas familiares en tiempos de Sorolla. Valencia, 2002, p. 246. 


\section{PINTORES DE LA ESCUELA SEVILLANA}

Existe una nutrida nómina de pintores hispalenses que abordan una interpretación personal del "monaguillismo", toda vez que forman parte de una de las escuelas más caracterizadas de toda la región en el seguimiento de la estética fortuniana y de la pintura de carácter social, tendencia y aspecto que son comunes en la práctica del tema.

Entre los primeros artistas hay que citar a José de la Vega Marrugal (18271896), pintor versátil, de cuya variopinta producción nos interesa destacar la obra titulada El oportunista ${ }^{6}$ (Figura 1), cuya datación en 1875 la sitúa entre las precursoras de la temática. En este sentido, hay que señalar que el protagonista de la simpática escena no es el proverbial monaguillo niño que veremos habitualmente, sino un novicio mozo que aprovechando el dormitar del fraile en su sillón tras la pitanza se dispone a apropiarse furtivamente de la botella de vino que se encuentra en la mesa.

Con independencia del jocoso asunto, la obra está bien compuesta, abordando el artista con detalle y minuciosidad una escena de interior que se desarrolla en el convento sevillano de dominicos, tal vez de San Pablo: la pequeña estancia más bien comedor improvisado con techumbre de vigas de madera, panel de alicatado, mueble librería rococó y cuadros en la pared, entre los que figura uno que representa a un Cristo nazareno de tipología sevillana.

La habitual vinculación de José María Rodríguez de Losada y de los Ríos (Sevilla, 1826-Jerez, 1896) con la pintura de historia no fue óbice para que al final de su carrera artística, cuando semejante temática estaba agotada aunque no desaparecida de los certámenes oficiales, acometiera un tema común al "monaguillismo": una escena de ritual sagrado. En este caso La primera misa, que se dispone a celebrar un recién ordenado sacerdote. La obra, fechada en 1892, nos muestra el interior de una sacristía en la que seis personajes, entre ellos dos diáconos, un fraile y un seglar, acompañan al flamante oficiante. En un extremo se hallan dos monaguillos, moreno uno y pelirrojo otro turiferario, que parsimoniosamente preparan la ceremonia.

A una segunda generación de pintores sevillanos pertenece José Villegas Cordero (1844-1921), vinculado estrechamente con la persona y la obra de Fortuny en Roma y también con la Academia Libre de Bellas Artes de Sevilla, a cuyos componentes se debe en gran medida el uso práctico y la enseñanza de la acuarela ${ }^{7}$.

Como autor de escenas de interior propias de la estética preciosista con representaciones de ceremonias o rituales sacros que evocan La vicaría del maestro

\footnotetext{
${ }^{6}$ Óleo sobre tela, 67 x $50 \mathrm{~cm}$.

7 Sobre esta institución, véase nuestro trabajo "La Academia Libre de Bellas Artes de Sevilla (1872-1888)”, Laboratorio de Arte, 11, 1998, pp. 275-300.
} 
de Reus, debemos mencionar una de las más representativas: la que lleva por título Bautizo en Sevilla. Fue expuesta en París en 1880 y se ignora su actual paradero aunque se conocen estudios previos con matices en el título ${ }^{8}$. La versión del Museo de Buenos Aires es una escenificación ceremonial en la que un conjunto de personas con trajes contemporáneos, pues no es un casacón, se agrupa ante el sacerdote oficiante que lee el libro litúrgico mientras varios monaguillos, algunos distraídos, ayudan al solemne acto. En este estudio previo, Villegas aboceta con pincelada muy espontánea y con manchas de color escasamente perfiladas. La composición se enmarca por una línea sesgada que va desde el sacerdote hasta las damas del primer término situadas en un extremo. Se advierte dinamismo en la acción, palpable en la diversidad de actitudes, que van desde la atención del oficiante y de la madrina hasta el enredo de los monaguillos, siguiendo por la conversación de las distinguidas invitadas y la rígida postura del criado de la izquierda que sustenta el azafate.

En relación también con el amor de Villegas por los efectos pictoricistas neorrománticos, conocemos una obra ejecutada a la aguada en torno a 1890 que representa el Interior de la capilla del obispo de Scalas de la catedral hispalense. Se compone de manera sencilla y efectista en el marco incomparable del enterramiento -vacío- del famoso prelado don Baltasar del Río, que fue obispo de Scalas (Nápoles), canónigo de la catedral hispalense y arcediano de Niebla.

Ante tan hermoso marco, se sitúa un monaguillo turiferario o turíbulo que viste túnica con sobrepelliz con cíngulo y se arrodilla para quemar incienso, mientras su compañero ceroferario transita parsimonioso tras él con rica dalmática portando un precioso libro coral en su brazo izquierdo.

Aprovecha Villegas el tema "monaguillista" para ofrecer detalles de la belleza del enterramiento realizado por Gazzini da Bisogne antes de 1539. En este sentido y como admirador y traductor de la tradición clásica italiana, nos ofrece el preciosismo de los elementos decorativos platerescos enmarcados por columnas abalaustradas: el tondo de la Virgen con el Niño -Nuestra Señora de la Consolación- y las imágenes de San Pedro y San Pablo todo ello en mármol blanco contribuyen a su ornamentación y hacen juego con el preciosismo de los indumentos de los acólitos que ocupan la estancia.

Para el pintor José García Ramos (1852-1912), con su gracejo característico, la presencia y la acción del monaguillo forma parte de su consustancial costumbrismo regionalista. Por este motivo, su figura la incorpora en las más diversas

${ }^{8}$ Una vez exhibida, la obra fue adquirida por William Vanderbilt, millonario norteamericano que la compra por 150.000 francos. CASTRO MARTÍN, Ángel: José Villegas (1844-1921). Córdoba, 2001, p. 61. Uno de los estudios previos se encuentra en el Museo de Bellas Artes de Buenos Aires, véase CRUZ VALDOVINOS, J. M.: 120 años de pintura española. Muestra en conmemoración del quinto centenario del descubrimiento de América. 1810-1930. Buenos Aires, 1991, pp. 84-85, 202 y 301. 
escenificaciones que representen la idiosincrasia de una tierra con la que se identifica plenamente. Son abundantes los dibujos que hizo de jóvenes acólitos para revistas de la época, como La Ilustración Artística y otras.

Nos interesa destacar algún cuadro suyo representativo de carácter efectista y escenográfico con la presencia de monaguillos. Tal es el caso del titulado Se aguó la procesión -o la fiesta- de la que se conocen al menos tres versiones con variantes que debieron ser ejecutadas en la última década del ochocientos y cuyo precedente está en alguna obra de Fortuny del mismo tema, parecido título y de más soltura técnica en la ejecución ${ }^{9}$. En dos de las versiones del pintor sevillano, es manifiesta la presencia en primer plano de jóvenes acólitos que se reportan en sus actitudes haciendo de turiferario y ceroferario en las procesiones de gloria y de penitencia, respectivamente ${ }^{10}$.

En otras ocasiones, García Ramos abordó el tema "monaguillista" de manera más convencional como sucede en su obra El viático, en el que dos oficiantes acompañados de varios caballeros portando faroles salen de la iglesia sevillana de San Esteban precedidos de un monaguillo.

A la escasamente conocida producción artística del sevillano Domingo Fernández González (1862-1918) corresponde una obra del tema que nos ocupa, fruto de su estancia en Italia desde 1886, como otros paisanos de su generación, tras la huella del maestro de Reus. En efecto, tal hecho se advierte en Interior de la catedral de Venecia ${ }^{11}$, que representa en medio del lujo oriental bizantino y en los primeros planos a cuatro figuras, dos de las cuales son monaguillos que portan objetos litúrgicos. Más al fondo, otros dos de ellos aparecen de espaldas portando el incensario.

Por su parte, Manuel García Rodríguez (1863-1925), pintor de gran sensibilidad dedicado especialmente al paisaje con figuras, aborda un excelente tema "monaguillista" titulado La Majestad. Se trata de un viático o procesión de enfermos e impedidos tan frecuente en la época de entresiglos, que solía salir en la época siguiente a Semana Santa desde la parroquia recorriendo las calles de la feligresía bajo repiques de campanas. En el cuadro, la comitiva, a cuyo paso se arrodilla devotamente un grupo de personas, trascurre en pleno día y está formada por el clero parroquial, las asociaciones piadosas y caballeros portando faroles.

${ }^{9}$ Nos referimos en concreto al titulado Salida de una procesión en día de lluvia de la iglesia de Santa Cruz de Madrid (1869) del que existen algunas versiones. Véase CRUZ VALDOVINOS, J. M.: 120 años de pintura española..., op. cit., pp. 66-67 y 197.

${ }^{10}$ Véase QUESADA, Luis: La vida cotidiana en la pintura andaluza. Sevilla, 1992, pp. 211-ss. También el catálogo de la exposición José García Ramos, un ilustrador de la vida sevillana. Sevilla, 1997, pp. 94-95.

${ }^{11}$ Óleo sobre lienzo, 70 x $51 \mathrm{~cm}$, firmado en Venecia. Colección particular de Barcelona. Véase el catálogo Figuras y escenas de interior en la pintura española. Burgos, 1987, p. 47. 
Nos interesa destacar el protagonismo de los monaguillos que ocupan los primeros planos: uno turiferario y otros esparciendo flores delante del cortejo.

De la misma generación que los dos artistas anteriores, estudioso en Roma y vinculado también al regionalismo artístico, José Rico Cejudo (1864-1939), nos ofrece una versión costumbrista de El bautizo al que incorpora elementos propios del preciosismo fortuniano - retablo, cuadros e indumentarias-, una vez más por influencia de La vicaría, cuyos modos tuvo ocasión de asimilar durante su estancia en Roma. Muestra el ritual cristiano en una capilla bautismal en la que se reúne un numeroso grupo compuesto por mujeres que lucen vestimenta ceremonial a base de mantillas blancas y negras y caballeros con capa. En medio de la composición se destaca un monaguillo de espaldas que permanece estático y fija su atención en la acción del oficiante.

En cambio, en otra obra titulada Interior de iglesia, Rico Cejudo se aleja del preciosismo fortuniano para adentrarse en una representación propia del realismo social, toda vez que domina en ella la piedad religiosa de tres mujeres enveladas recogidas en sus rezos en una capilla poco iluminada. Abona la temática la presencia de un anciano que porta bastón y sombrero, y la de un monaguillo de espaldas dirigiéndose a una de ellas ${ }^{12}$.

La siguiente generación de pintores sevillanos se libera de ciertos convencionalismos en el tema e incorpora un tipo de representación más desenfadada en la que la presencia del joven acólito provoca a veces la reprobación de los oficiantes y en ocasiones la hilaridad de los espectadores ajenos a la ceremonia.

A esta generación pertenece Manuel González Santos (1875-1949). De temática diversa, abordó ocasionalmente el "monaguillismo" como en su obra titulada Fin de fiesta $(1896)^{13}$. Se trata de la acción en los primeros planos de dos de estos jóvenes personajes en las escaleras del altar de una iglesia tras la conclusión de una solemne ceremonia. Uno vestido con lujosa dalmática porta un libro sagrado y el otro con muceta roja y alba recoge el incensario, una bandeja y una campanilla (Figura 2). Más al fondo, en el propio altar, un niño entrega un ramo de flores al sacristán para que lo coloque en el retablo al pie del Crucificado.

Vinculado al tardo regionalismo de la posguerra, Alfonso Grosso Sánchez (1893-1983) sigue fiel a la temática costumbrista en escenas de interior conventuales que en Sevilla encontraban eco aún rebasada la mitad del nuevo siglo. Muestra de ello mencionaremos dos de sus obras vinculadas al tema que nos ocupa.

En El monaguillo (1920), lejos de representar a semejante personaje en su habitual ambiente acompañado por otro en la sacristía o en la capilla bautismal y

12 Óleo sobre lienzo, 73 x 100,5 cm. Colección particular.

13 Óleo sobre lienzo, 72 x $45 \mathrm{~cm}$. Colección particular. Hemos intentado ubicar la escena y pudiera tratarse del altar del Cristo de la Expiración de la parroquia de San Nicolás de Sanlúcar de Barrameda. Agradezco al doctor don Fernando Cruz Isidoro su ayuda para la identificación. 
rodeado de retablos, cuadros y cajonerías, lo hace en esta ocasión de manera individual en un espacio inconcreto y vacío posando fijo ante el espectador. Grosso se centra en la figura del jovencito vestido con lujosa dalmática sobre el alba, con las manos unidas, que esbozando una sonrisa manifiesta una franca ingenuidad al tiempo que un placer en su oficio ${ }^{14}$.

Por su parte, La comunión de una novicia del convento de Santa Clara (Figura 3) muestra al sacerdote administrando el sacramento a través de la ventana del comulgatorio conventual, mientras en primer plano como introductores de la escena dos monaguillos sosteniendo la patena y la campanilla miran sonrientes al espectador.

\section{LAS ESCUELAS DE JEREZ Y DE CÁDIZ}

Jerez de la Frontera, merced al auge alcanzado por su población gracias a los negocios vinícolas, posee en el siglo XIX escuela artística propia con referencia estilística y temática en la de Roma a través de Sevilla. Sus pintores gozarán de justa fama en Andalucía y fuera de ella ${ }^{15}$.

La idiosincrasia de una ciudad que fue sede de distinguidas familias nobles y alto burguesas se pone de manifiesto en ostentosos acontecimientos sociales de carácter religioso celebrados en el altar mayor, en la sacristía o en la capilla bautismal de la catedral o de alguna de las espléndidas iglesias parroquiales en las que no faltaban para su lucimiento la participación de un número considerable de oficiantes, diáconos, cantores corales y monaguillos con sus mejores atuendos litúrgicos.

Este lujo ambiental de indumentarias y objetos preciosos encuentra su mejor aliado en la estética representada por Fortuny y su Vicaría. Es la senda seguida por los mejores pintores jerezanos de la segunda mitad del ochocientos.

A destacar, José Gallegos Arnosa (1859-1917), considerado no solo como uno de los artistas más representativos de la escuela pictórica jerezana sino también una referencia a nivel internacional dentro de la llamada Escuela de Roma. Su producción artística alcanza las más altas cotas debidas a su técnica y a su fecundidad creativa haciéndose con el mercado artístico de su tiempo siguiendo la huella del maestro reusense.

La temática "monaguillista" se convierte en Gallegos en una suerte de sugestiva "obra sacramental", no por su asunto religioso sino por la representación de interiores donde se celebran fiestas notables y fastuosas de culto católico.

\footnotetext{
${ }_{14}$ Óleo sobre lienzo, 127 x $92 \mathrm{~cm}$. Museo de Bellas Artes de Sevilla.

${ }^{15}$ Véase DE LA BANDA Y VARGAS, Antonio: "La pintura jerezana en el siglo XIX", Archivo Español de Arte, 273, 1996, pp. 86-95.
} 
Sus obras de esta temática ejecutadas entre 1885-1890, una vez agotada la práctica del cuadro orientalista, gozan de un especial atractivo ya que aúnan al preciosismo técnico de vibrante colorido y lujosas texturas y entonaciones, el aliciente de la escenificación de los monagos a veces distraídos en plenos oficios religiosos con más frecuencia en el coro.

Tablitas como las tituladas Preparando la procesión, La procesión (Venecia), La primera comunión, Bautizo en la catedral de Sevilla, El coro (Figura 4) y Viernes Santo se convierten en verdaderos alegatos a un género que con él pasa de ser una valiosa pieza meramente decorativa en la que brillan rejas, púlpitos, atriles y colgaduras, a una auténtica joya pictórica que en ocasiones se enrique con la jocosidad que provocan los monaguillos.

Su paisano y compañero en Roma, Salvador Sánchez-Barbudo y Morales (1857-1917), siente menos interés por el tema que estudiamos pero no se resiste a interpretar iconográficamente alguna obra en que se halla presente algún jovencito con ropas talares. Tal es la titulada Interior de catedral, ambientada en una nave de San Marcos de Venecia. Un cardenal de larga capa roja lee arrodillado ante un atril en presencia de una multitud y de dos monaguillos que charlan entre sí ajenos a lo que acontece a su alrededor ${ }^{16}$.

Pintor perteneciente también a la Escuela de Roma, mayor en edad que los anteriores, menos popularidad que ambos, y autor de una producción muy diversa en temática, Germán Álvarez Algeciras (1848-1912), nos ofrece uno de los cuadros más representativos del "monaguillismo" español: El interior de la sacristía de San Miguel de Jerez (1905). La obra se enmarca, una vez más, en la tradición fortuniana como eco ya lejano de la estancia de su autor como pensionado en Roma (1871-1878), pero al mismo tiempo comparte la estética de la pintura social finisecular. La acción se desarrolla en la sacristía, que parece evocar la de la Vicaría del maestro de Reus por la colocación de la reja de fondo y otros objetos, pero los protagonistas son ahora casi exclusivamente los cuatro monaguillos que ajenos a la llegada del cura que entra por el fondo se divierten jugando con unos objetos litúrgicos.

Por su parte, la capital gaditana con fuerte arraigo cultural y artístico desde los inicios de la centuria decimonónica, mantiene durante la Restauración monárquica y el primer tercio del novecientos un prestigio consolidado en la estética del Realismo, al que contribuyó tanto la Academia y su Escuela de Bellas Artes como la personalidad de un plantel de buenos artistas locales y foráneos ${ }^{17}$.

${ }^{16}$ Se trata de un óleo sobre tabla, 38,5 x $25 \mathrm{~cm}$. Véase el catálogo de la exposición Salvador Sánchez Barbudo. Jerez, 1997, s. p.

${ }^{17}$ Para lo referente a la pintura gaditana del período que estudiamos, véase PÉREZ MULET, Fernando: La pintura gaditana (1875-1931). Córdoba, 1983. 
A la producción de obras historicistas siguió la práctica en Cádiz de otros géneros, entre ellos el de carácter social, a veces abonados con un preciosismo fortuniano como el que nos ocupa en este trabajo.

Tal vez sea Salvador Viniegra y Lasso de la Vega (1862-1915) el pintor de la escuela gaditana más comprometido y eficiente en la práctica del "monaguillismo", al que ennobleció con obras muy celebradas por la crítica y el público. La razón pudiera estar en que su personalidad se identifica con la tradición de una burguesía local educada y culta que gusta mantener un boato ceremonial en los actos litúrgicos, aún al aire libre, en los que la presencia del monago es casi obligada. Pero también y sobre todo se justifica porque Viniegra es uno de los artistas más representativos de la segunda generación de pintores españoles formados en Roma y como tal admirador de Fortuny, de su Vicaría y de los incondicionales seguidores del maestro como Villegas ${ }^{18}$.

$\mathrm{Su}$ obra más representativa es la titulada La bendición de los campos en 1800, merecedora de primera medalla en la Exposición Nacional de $1887^{19}$. Con ella -se ha dicho-inicia la galería de estampas raciales en las que España queda confundida con Andalucía ${ }^{20}$. Como si de un gran telón a modo de cuadro de historia se tratase, una multitud de fervorosos campesinos asisten a la piadosa ceremonia. En los primeros planos ante el paso mariano se encuentran junto al oficiante, con hisopo y libro, dos monaguillos afrontados que, respectivamente, balancea y rellena el incensario. Otros dos que se sitúan a la derecha del espectador en medio de una tenue iluminación actúan de ceroferarios.

Unos años después, Viniegra ejecuta otras obras que podemos situarlas en la órbita de nuestro tema. La titulada Un bautizo en España (1890) nos ofrece una versión "mutatis mutandis" de La vicaría de Fortuny. Ahora, una hermosa capilla bautismal se convierte en el marco preciosista para la ceremonia de cristianizar a una criatura ante la concurrencia familiar y amistosa, el oficiante y los monagos.

Nacimientos y defunciones es el título de otra obra de este mismo pintor gaditano que, vinculada al "monaguillismo" y alejada ahora del estilo de Fortuny, se halla más en línea con la pintura de carácter estrictamente social. Muestra las dos caras de la vida en el ámbito de la religión y de la familia, ya que simultáneamente representa a izquierda y derecha una escena de inscripción de nacimiento y otra de notificación de defunción respectivamente ${ }^{21}$. Mientras, el monaguillo situado en el primer plano compositivo y ajeno a lo que ocurre a su alrededor, aviva el fuego del brasero.

${ }^{18}$ En 1882 llega a la Ciudad Eterna, en donde permanecerá la mitad de su vida. Véase GONZÁleZ, C. y MARTÍ, M.: Pintores españoles en Roma. Barcelona, 1987, p. 237.

19 Óleo sobre lienzo, 345 x $916 \mathrm{~cm}$. Museo de Bellas Artes de Málaga.

20 PÉREZ MULET, F.: La pintura gaditana..., op. cit., p. 126.

${ }^{21}$ Catálogo de la exposición Ternura y melodrama. Pintura de escenas familiares en tiempos de Sorolla. Valencia, 2002, pp. 246-247. 
La escuela artística gaditana se preció de contar en el siglo XIX con algunas destacadas mujeres artistas, tal es el caso de la neoclásica Victoria Martín del Campo, a quien de alguna manera sucedería en mantener el prestigio femenino en la ciudad la gaditana Alejandrina Gessler de Lacroix, conocida como "Madame Anselma" (1831-1907). Hija del cónsul ruso en la ciudad, fue alumna de la escuela local de Bellas Artes y vivió en París al casarse con un diplomático francés lo que le permitió conocer a Bonnat y Gêrome y exponer allí a nivel internacional $^{22}$.

La elegancia y distinción de mujer tan cosmopolita se advierte en su producción artística en la que domina un estilo acabado y preciso de rasgos académicos. Tales son los que se encuentran en su obra titulada La adoración de la Cruz en Jueves Santo (Figura 5), que, ejecutada durante su estancia en Francia, obtuvo la medalla de oro en la Exposición Provincial de Bellas Artes de Cádiz en 1878, y donada a la Academia local por la autora como reconocimiento a su ingreso en la corporación ${ }^{23}$. Con independencia de las identificaciones que se han hecho de los personajes representados así como de la datación de la obra ${ }^{24}$, nos interesa ahora señalar la presencia del monaguillo de pie vestido con ricas ropas litúrgicas y ocupando un primer plano compositivo.

El pintor chiclanero Eduardo Vasallo Dorronzoro (1868-1932), de escasa producción por su dedicación especial a la enseñanza que ejerció en Cádiz, Santiago, Madrid, Córdoba y Baeza, como artista de su tiempo no pudo sustraerse a la práctica de alguna representación propia de la temática que estudiamos. A tal efecto, su obra El coro $(1898)^{25}$ es una versión personal del tema tan ampliamente tratado por los artistas de su generación con los precedentes estilísticos ya comentados con anterioridad.

\section{LOS PINTORES CORDOBESES}

La Córdoba de la Restauración inició un esperanzador proceso cultural y artístico que culminaría en las primeras décadas de la nueva centuria, sacando de la mediocridad el ambiente romántico y posromántico en que se encontraba y propiciando así la entrada en la era del Realismo y la creación de una brillante

${ }^{22}$ Para ver el estado de la cuestión sobre la pintora, ILLÁN MARTíN, Magdalena: "La pintora andaluza Madame Anselma en Francia: nueva aportación al catálogo de su obra", Laboratorio de Arte, 7, 2015, pp. 659-667.

${ }^{23}$ Óleo sobre lienzo, 64 x $82 \mathrm{~cm}$. Museo de Arqueología y Bellas Artes de Cádiz.

${ }^{24}$ Según el parecer de César Pemán, la señora representada era la reina María Cristina y la niña junto a ella, la infanta María de las Mercedes. Catálogo del Museo de Cádiz, 1964, p. 187. Respecto a la cronología del cuadro, mientras Illán Martín la considera de 1869, la ficha oficial del Museo de Cádiz la pospone entre 1872 y 1878.

${ }^{25}$ Es un óleo sobre tabla, de 26 × $33 \mathrm{~cm}$. Pertenece a una colección particular de Madrid. 
escuela artística local de la mano de grandes maestros como Romero Barros y sus hijos los Romero de Torres.

Si bien esta familia de pintores se vinculó a los géneros y asuntos comunes en su tiempo, entre los que figuró de manera destacada la pintura realista de temática social, debemos citar ahora por su singularidad a Rafael Romero de Torres (1865-1894) a propósito de una obra finisecular que comparte la temática que estudiamos. Se trata de la que desde Roma remite a la Diputación en 1890 titulada Los últimos sacramentos ${ }^{26}$. Con el precedente de su cuadro también de temática social dedicado al paro laboral que había ejecutado dos años antes, compone la escena de manera parecida en formato e intencionalidad: en una humilde estancia, un hombre postrado en un colchón con la cabeza vendada se dispone a recibir los postreros auxilios espirituales de un sacerdote al que acompaña un monaguillo que porta un gran farol encendido cuyo peso le obliga a utilizar ambas manos.

\section{LOS PINTORES MALAGUEÑOS}

La moderna escuela artística malagueña que encabezara el valenciano Bernardo Ferrándiz una vez posesionado en 1868 de la cátedra de Pintura y Copia de Cuadros en la Escuela de Bellas Artes, constituyó el motor de arranque del prestigio de los artistas formados bajo su magisterio, quienes comenzarían a practicar un tipo de cuadro de género que tendría manifiesta fortuna ya que significaba la moda del momento basada en la autenticidad a través de la observación y ulterior plasmación de la realidad, pese a que ésta se mirara e interpretara fragmentada en un ejercicio que preparaba el Realismo sin lograrlo aún.

Pese a la indudable influencia que ejerció el citado maestro levantino en la escuela artística malagueña, no fue la única, ya que algunos, como el destacado Moreno Carbonero, optaron por tomar su propio camino que les conduciría también a altas metas a la vez que diversificaría positivamente la escuela.

Soslayamos por razones obvias profundizar en estos momentos sobre la dedicación del malacitano Picasso a la temática "monaguillista", recién llegado a Barcelona en 1895, como versión de un subgénero dentro del realismo social. Citemos solo obras como Primera comunión (1896) y El monaguillo. En ésta, entra de lleno en la contestación social.

Joaquín Luque Roselló (1860-1936), regresa a Málaga, su ciudad natal, en la última década del siglo tras su estancia en Roma cerca de Villegas y Viniegra. Allí permanecerá unos años antes de su marcha a Galicia en 1905 como profesor y cuatro años después a Argentina donde morirá.

Este breve ínterin en la bella ciudad mediterránea supone para el pintor consumar una estética afín a las escuelas de Sevilla y Cádiz a través de los artistas

${ }^{26}$ Óleo sobre lienzo, 318 x $210 \mathrm{~cm}$. Museo de Bellas Artes de Córdoba. 
antes citados, más que débito a los pintores malagueños a pesar de que en 1878 fue alumno de Ferrándiz en la Escuela de Bellas Artes de San Telmo ${ }^{27}$. Y sus frutos se materializan en un cambio temático que contrae como propio practicando la pintura de género de corte preciosista a lo Fortuny pero manteniendo al mismo tiempo la solemnidad, el lujo ambiental y el acopio de personajes propios de la pintura de historia ${ }^{28}$.

Obras como las tituladas Primera comunión (1895) y Voto de matrimonio (1897) son consecuencias de la gracia y espontaneidad hispalense y gaditana asumidas por su autor como sugestivas representaciones costumbristas propias de la Escuela de Roma.

La primera citada, muestra una solemne ceremonia eucarística que transcurre en un fastuoso interior catedralicio o templario y está compuesto por una procesión de dos filas de niñas vestidas con primorosos trajes blancos, portan cirios encendidos y flanquean al cura oficiante que discurre sobre alfombra roja acompañado de varios monaguillos, dos a su lado y otros tres llevando faroles y ciriales. En un extremo del cuadro un grupo de feligreses con atuendos a la goyesca contempla el cortejo.

En cuanto a la obra titulada Voto de matrimonio ${ }^{29}$ (Figura 6) es una versión personal de una boda gitana interpretada de manera ostentosa y al tiempo popular, toda vez que está concebida como si de una ceremonia burguesa se tratase con el detalle de tipismo de ser un torero el novio. Los invitados a la ceremonia parece que participan de una fiesta profana y las damas recuerdan en extremo a otras representaciones pictóricas de descanso de los diestros. Mientras ellas, indiferentes al altar y lo que allí ocurre, coquetean descaradamente con sus acompañantes ataviados con el traje de luces como también el contrayente, y ellas con unos atavíos ajenos a los propios de las gitanas ${ }^{30}$.

Nuestro interés en esta obra es destacar la acción de los monaguillos: uno situado en el centro de la composición porta a duras penas un gran libro coral ante el regocijo de su compañero que parece ajeno a la celebración; mientras, otro monaguillo se dispone a encender un cirial de altar.

Por su parte, el pintor Antonio María Reyna Manescau (1859-1937) permaneció en Málaga -nació en Coín- hasta 1882 en que obtiene una pensión para Roma y allí se relaciona con los fortunianos españoles entre ellos numerosos andaluces. Cabe, pues, incluirlo como pintor de la Escuela de Roma, ciudad en la que falleció.

27 Véase el catálogo de la exposición Blanca y Radiante. Desde la invisibilidad a la presencia en el universo femenino. Málaga, 2008, p. 164.

${ }^{28}$ Es lo que hace José Villegas en su gran obra La muerte del torero, óleo sobre lienzo, 330 x $505 \mathrm{~cm}$, colección particular, Madrid.

29 Óleo sobre lienzo, 67 x 123 cm. Colección Peñarroya, Málaga.

${ }^{30}$ Blanca y Radiante..., op. cit., p.167. 
Su producción artística se versifica, entre la práctica del paisajismo urbano de Venecia convirtiéndose así en un continuador de la tradición paisajística de la ciudad de los canales, y los cuadritos de casacón y escenas de la vida cotidiana. Entre estos últimos, pintó alguno adscrito al "monaguillismo", que alguien llama subgénero dentro de la temática costumbrista. Se trata del cuadro titulado Partida en la sacristía ${ }^{31}$, que ahora introduce en el tema el desenfado propio de las travesuras de jóvenes monaguillos en su lugar de actividad. Se trata de tres mozalbetes, dos de ellos monagos, sentados en el suelo de la sacristía que disputan una partida de cartas mientras un cuarto, que parece recién llegado, les observa de pie (Figura 7).

Con esta obra su autor responde a una visión bien distinta de aquellas otras interpretaciones del tema -algunas ya vistas- en que primaba el boato del lugar y el lujo en las indumentarias litúrgicas de oficiantes y monaguillos que permanecen en actitud pasiva y contenidos en sus ademanes ceremoniosos. Por el contrario, ahora manifiesta justamente un sano e incluso humilde "monaguillismo" que está presente en la sencillez de la sacristía y en el carácter pícaro e inocente del personaje, lo que atrae a un público poco exigente con la temática y más proclive a valorar una escena intrascendente pero llena de gracia e ingenuidad.

\section{A MODO DE COLOFÓN A UN TEMA: LA INTERPRETACIÓN "MONA- GUILLISTA” DE SÁNCHEZ SOLÁ}

Entre los autores de esta última citada recreación del tema, pletórica de alborozo y divertimento, cabe aludir de manera sobresaliente a Eduardo Sánchez Solá (1869-1949), quien, aunque nacido en Madrid, se le ubica al ámbito granadino, en cuya Escuela de Artes, Industrias y Bellas Artes ejerció la docencia en pintura y arte decorativo.

Se le suele llamar "el pintor de los monaguillos" por su especial vinculación a este subgénero costumbrista, por lo común ambientado en iglesias andaluzas, al que dedicó buena parte de su obra con habilidad e imaginación.

El interés de sus creaciones radica en mostrar la acción dinámica de los más variopintos juegos y travesuras llevados a cabo generalmente en las sacristías por inquietos monagos vestidos de tales, interpretando al mismo tiempo sus pícaros gestos y actitudes, como son: simular la acción de un torero de entrar a matar, jugar a las cartas, saltar a piola, fumar, pelearse entre compañeros, etc. (Figuras 8-10).

Tanto gusta a Sánchez Solá la figura del monaguillo que no se arredró en colocar un par de ellos, en primerísimo plano y moviendo con brío los incensarios, en la simbólica representación apoteósica al modo barroco que ofrece en la decoración pictórica de la bóveda del camarín de la Virgen de las Angustias en la

${ }^{31}$ Óleo sobre lienzo, 70 x $45 \mathrm{~cm}$. Colección particular. 
basílica de esta advocación en Granada, que efectuó el pintor en 1916 como parte de la restauración del lugar tras el incendio sufrido el 26 de julio de ese año ${ }^{32}$.

La obra en formato elíptico escenifica el momento de la solemne coronación canónica de la patrona de la ciudad el 20 de septiembre de 1913 a cargo del arzobispo de la diócesis monseñor José Meseguer y Costa (1843-1920), acompañado de varios oficiantes solemnemente vestidos y de los citados monagos. El prelado se dispone a coronar a la imagen entronizada en lugar elevado como cúspide del mundo y en medio de un luminoso celaje en el que revolotean simbólicas palomas blancas.

Fecha de recepción: 30 de septiembre de 2016

Fecha de aceptación: 4 de enero de 2017

${ }^{32}$ Las llamas arrasaron el camarín por lo que tuvo que ser restaurado bajo la dirección del escultor valenciano José Manuel Garnelo Alda. La gran mayoría de pinturas desaparecerían y otras quedaron muy dañadas, por lo que este último encargó su restauración al pintor cordobés Esmaragdo Pérez. 

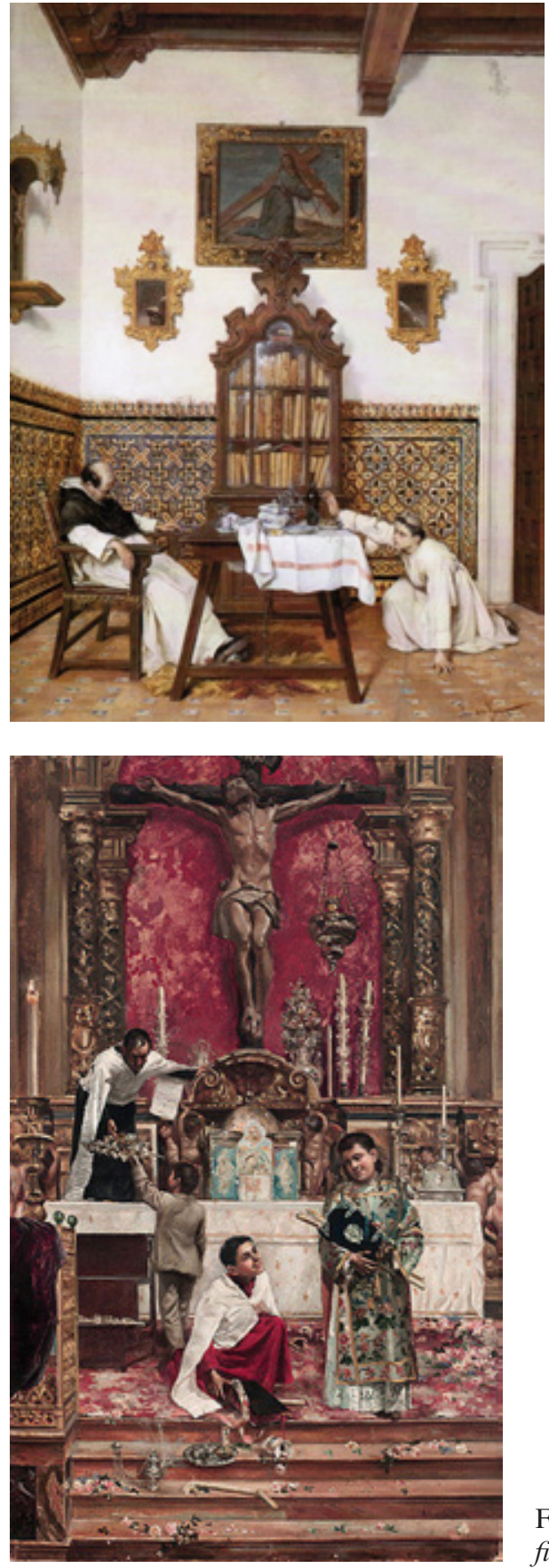

Figura 1. José de la Vega Marrugal, El oportunista, 1875, colección particular.

Figura 2. Manuel González Santos, Fin de fiesta, 1896, colección particular. 
Figura 3. Alfonso Grosso, La comunión de la novicia, Museo de Bellas Artes de Sevilla.
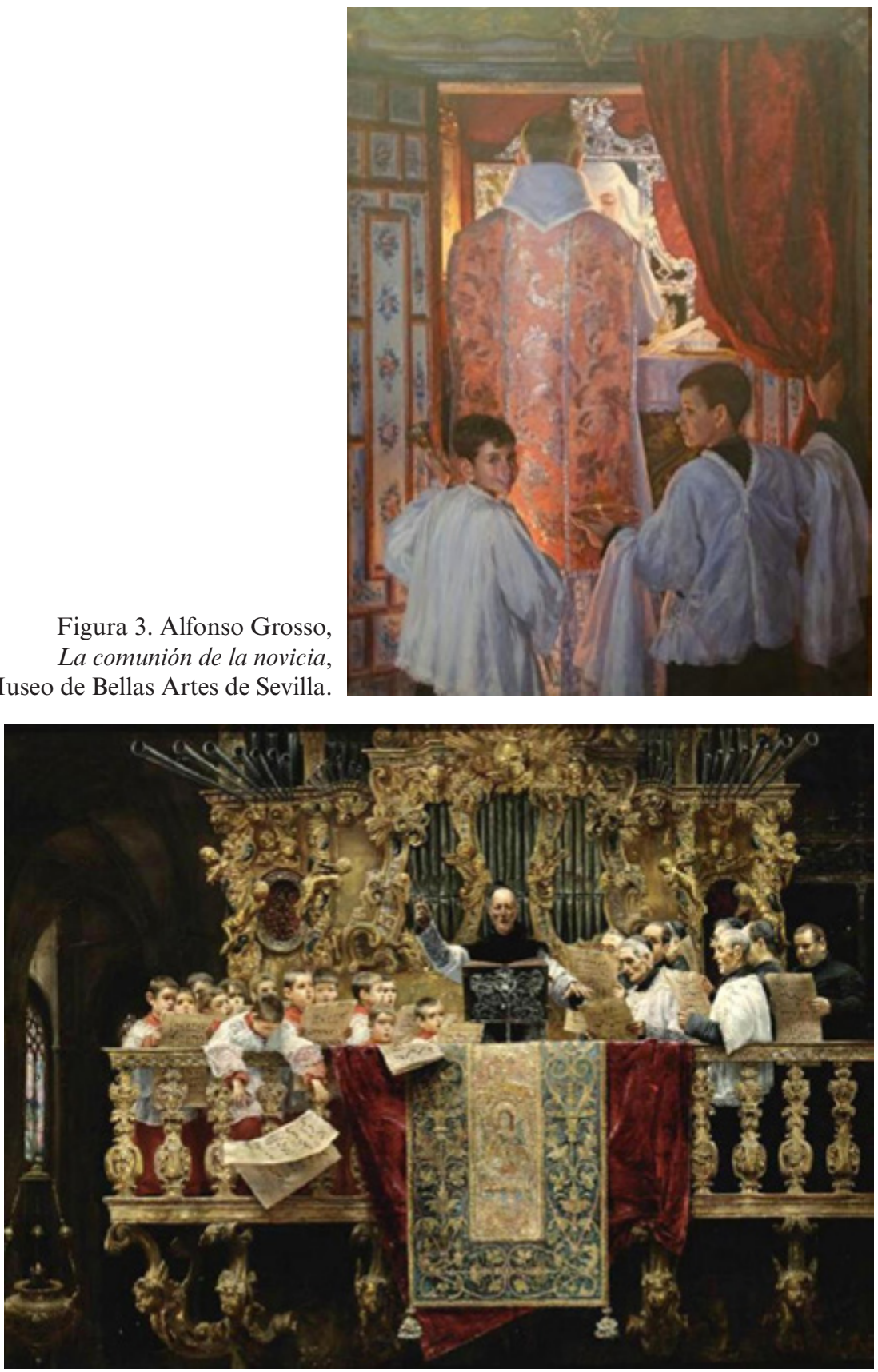

Figura 4. José Gallegos Arnosa, El coro, 1886, colección particular.

LABORATORIO DE ARTE 29 (2017), pp. 653-672, ISSN 1130-5762 e-ISSN 2253-8305 - DOI http://dx.doi.org/10.12795/LA.2017.i29.36 


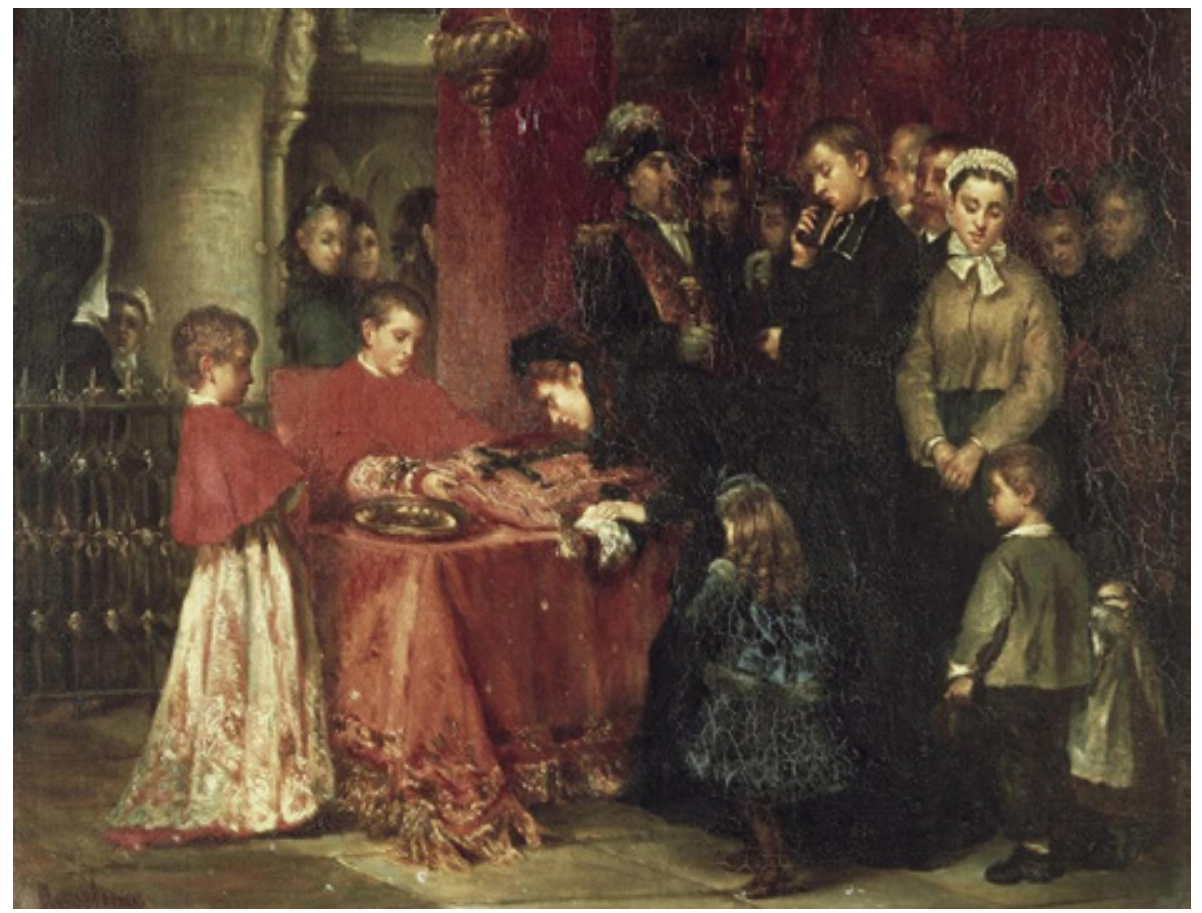

Figura 5. Alejandrina Gessler, La adoración de la Cruz en Jueves Santo, 1869, Museo de Cádiz.

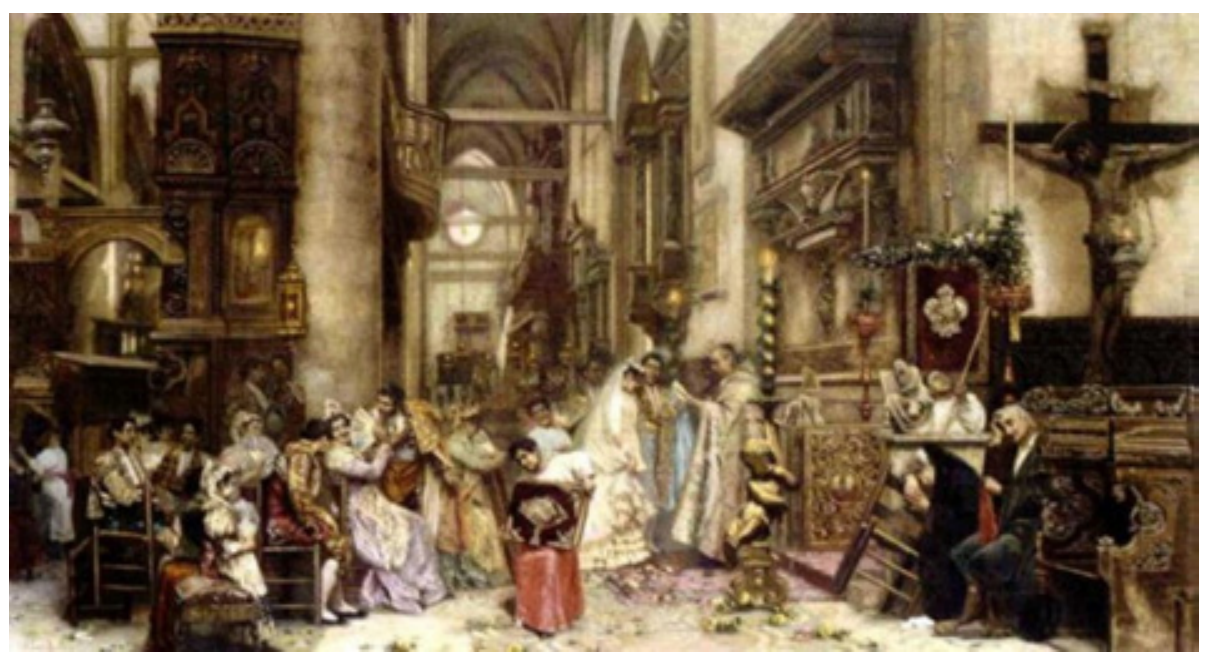

Figura 6. Joaquín Luque Roselló, Voto de matrimonio, 1897, colección Cristóbal Peñarroya, Málaga. 
Figura 7. Antonio Reyna Manescau, Partida en la sacristía, colección particular.

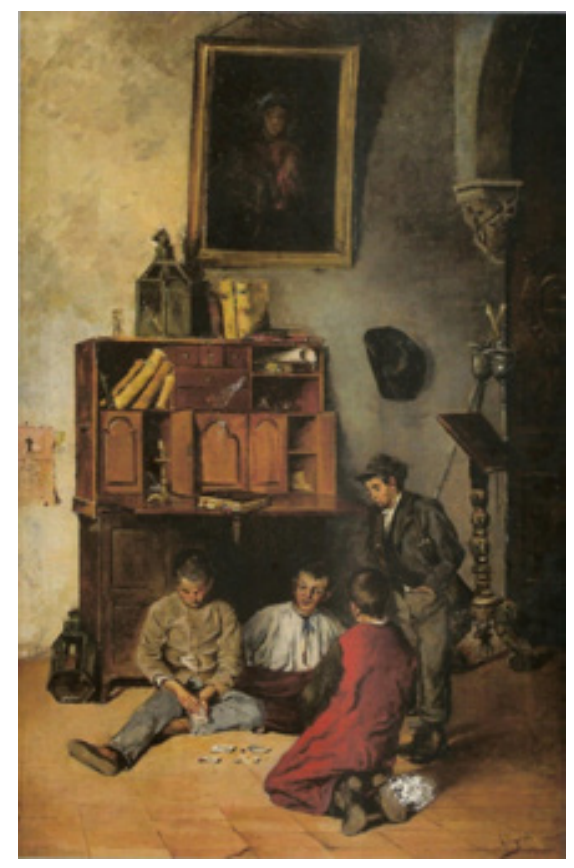

Figura 8. Eduardo Sánchez Solá, Corto y ceñido, colección particular.

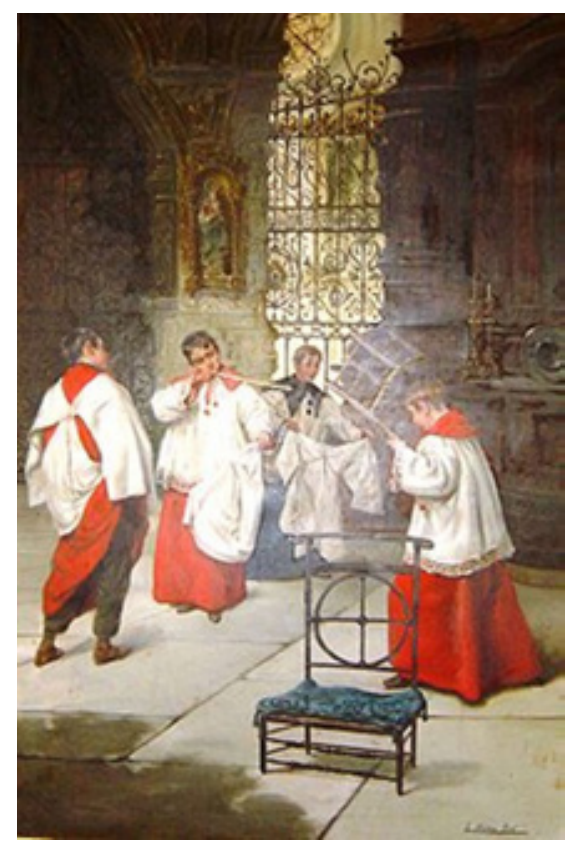

LABORATORIO DE ARTE 29 (2017), pp. 653-672, ISSN 1130-5762 e-ISSN 2253-8305 - DOI http://dx.doi.org/10.12795/LA.2017.i29.36 


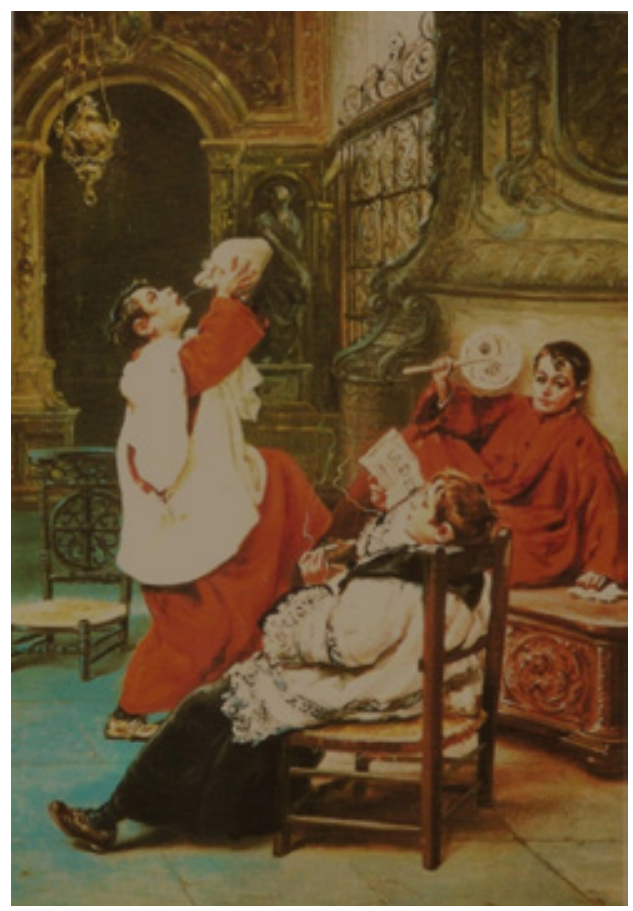

Figura 9. Eduardo Sánchez Solá, Monaguillos, colección particular.

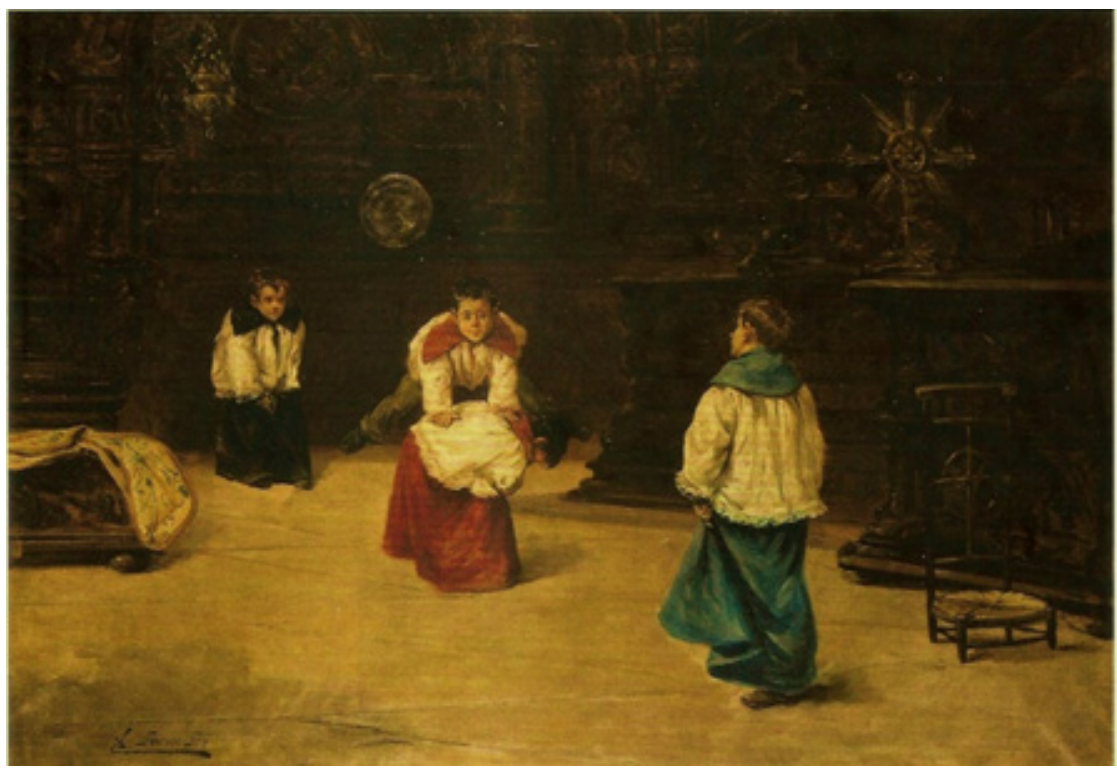

Figura 10. Eduardo Sánchez Solá, Jugando a piola en la sacristía, colección particular. 